\title{
Morphology and a proposed model of innervation of the human deltoid muscle: a pilot study
}

\author{
G. Wysiadecki ${ }^{1}$, M. Polguj² ${ }^{2}$ K. Krasucki ${ }^{3}$, A. Żytkowski ${ }^{1}$, J. Śmigielski ${ }^{4}$, M. Topol ${ }^{5}$, S. Orkisz ${ }^{1}$ \\ ${ }^{1}$ Department of Normal Anatomy, Medical University of Lodz, Poland \\ 2Department of Angiology, Medical University of Lodz, Poland \\ ${ }^{3}$ Department of Descriptive and Clinical Anatomy, Centre of Biostructure Research, Medical University of Warsaw, Poland \\ ${ }^{4}$ Department of Informatics and Medical Statistic, Medical University of Lodz, Poland \\ ${ }^{5}$ Department of Normal and Clinical Anatomy, Medical University of Lodz, Poland
}

[Received 28 November 2013; Accepted 26 December 2013]

Background: The deltoid muscle (DM) plays an essential role in retaining the stability and correct function of the upper limb. The aims of the study were to perform a detailed morphological analysis of the DM including its innervation, structure, attachments and relationship with adjacent structures.

Materials and methods: The study was carried out on 17 formalin-fixed cadaveric upper limbs. After dissection of the shoulders, the DM was visualised and analysed. The following measurements of the muscle were performed for all cases: width of attachments (acromial, clavicular, spinal), entire width of origin, length of the component parts (acromial, clavicular, and spinal) and length of the arm. Results: In all specimens, a characteristic 'segmented' innervation scheme of the $D M$ was observed. The axillary nerve (AN) was always divided into an anterior branch (abAN) and a posterior branch (pbAN). Two variations of the DM innervation were distinguished: variation I, where the clavicular and the acromial parts were innervated by the abAN, while the spinal part was supplied both by abAN (anterior fibres) and by pbAN (posterior fibres), and variation II, in which the spinal part did not have double innervation - the abAN innervation area covered only the acromial and clavicular parts, and the entire spinal part was supplied by pbAN. Both variations had a segmented arrangement of sub-branches reaching individual parts of the DM, which was particularly distinct in the clavicular and acromial parts. Correlations were found between the entire width of the DM origin and the length of the arm $(p=0.001)$, between the length of the acromial part of the DM and the length of the arm $(p=0.003)$, between the width of the spinal attachment and the length of the spinal part $(p=0.002)$, and between the width of the spinal attachment and the length of the arm $(p=0.0008)$.

Conclusions: The study confirmed the existence of a characteristic segmented innervation scheme of the DM which corresponds with the segmented morphology of its individual parts. An analysis of the internal structure of the muscle specific architectonics based on the tendon system was also presented. (Folia Morphol 2014; 73, 2: 216-223)

Key words: deltoid segments, deltoid architecture, innervation pattern, anthropometric measurements of the deltoid 


\section{INTRODUCTION}

The deltoid muscle (DM) plays an essential role in retaining the stability and correct function of the upper limb [29, 31]. The DM is innervated by the axillary nerve (AN), running in the vicinity of the surgical neck of the humerus [29, 37]. The position of the AN is, however, associated with greater risk of damage, potentially resulting in paralysis or paresis of the DM $[2,32,38]$. There have also been recorded cases of AN paralysis following intramuscular injections in the DM region $[9,11]$. The risk of damage to the shouIder region is exacerbated by the fact that it is also frequently operated on [7, 8, 22, 32, 38].

Biomechanical models of the musculoskeletal system are often used in practice for the purpose of studying muscle coordination and simulating the effects of surgical procedures, e.g. joint replacements or tendon transfers [17, 26]. Data used in creating such models has, to a large extent, been obtained by anatomy research [17]. Procedures such as glenohumeral $(\mathrm{GH})$ joint endoprothesoplastic surgery or repair operations of fractures located in the proximal end of the humerus require surgical intervention in the $D M$ region $[22,23,25,32,38]$. Another surgical technique performed in this area is transfer of the spinal part of the DM to the long head of the triceps in order to enhance extension at the $\mathrm{GH}$ joint in patients with radial nerve palsy $[10,14]$. Hence, the precise morphology and the nature of the innervation of the DM are clinically relevant and should be of interest to trauma surgeons and anatomists.

The DM can be divided into three parts: anterior-clavicular, middle-acromial and posterior-spinal. However, the functions of the individual parts of the DM vary [29, 31, 37]. Recent studies have additionally suggested that the DM consists of a few anatomical and functional segments which may, to a large extent, be independently coordinated by the nervous system $[3,5,15,34,40]$. Specific issues concerning the relationship between the innervation and the muscle segments of the DM were not described, even in the latest research of Sakoma et al. [34], from 2011.

Taking into account the functional aspects, including the concept of anatomy trains used in physiotherapy, it seems also reasonable to analyse connections of the DM with the adjacent muscles, mainly particularly with fascial structures [30, 33].

The aims of the study are: (1) To analyse the DM structure and confirm whether there is a scheme of the DM innervation corresponding to the segmen- ted morphology of the muscle; (2) To make a detailed description of the parameters of individual DM attachments; (3) To present a wider view of the anatomical connections of the DM to the adjacent structures by fascial structures.

\section{MATERIALS AND METHODS}

For the purpose of the study, 17 upper limbs (9 right and 8 left) fixed in a $10 \%$ formalin solution were used as specimens. Only those limbs with an anatomical position at the GH joint were selected. Any specimen displaying deformations, injuries and scars in the shoulder and arm region were excluded prior to admission. The research project and all procedures were approved by the Bioethics Commission of the Medical University of Lodz (protocol no. RNN/491/11/KB).

At the initial stage of the dissection, classic methods were used: cautious removal of skin along with subcutaneous tissue from the shoulder and arm region while retaining the fascia. Following this, the lengths of the individual parts of the DM were measured, as well as the width of their attachments. Anthropometric points were indicated with pins. Each measurement was repeated to an accuracy of within $1 \mathrm{~mm}$, and the average of both measurements, rounded up to $1 \mathrm{~mm}$, was accepted as the final result.

The acromial end of the clavicle was accepted as the borderline between the anterior part and the middle part of the DM. The boundary between the middle and the posterior parts runs along the bony landmark called 'acromial angle' of the scapula [37], distinguishable in all the cases as a palpable lump. A pin was put in the humerus in the most distal point of the DM insertion on the deltoid tuberosity. As described by Fridén and Lieber [14], length measurements of the clavicular and spinal parts of the DM were taken along their external edges, while the acromial part of the DM was measured at the midline. At this stage of the dissection, it was also possible to follow the connections between the fascia enveloping the DM and the adjacent structures.

After the measurements were taken, the origin of the DM was dissected to visualise the inner surface of the muscle, along with the AN. While dissecting the muscle, connections between the DM and the infraspinous fascia were observed. Next, the neurovascular bundle was dissected in the quadrangular space. The blood vessels were resected. Upon visualisation, AN branches reaching particular parts of the DM were marked with pins of different colours. Thus, it was 
possible to precisely observe the scheme of DM innervation by individual branches of the AN.

The final stage of the study consisted of an assessment of the segmented morphology of the DM on 6 isolated muscle specimens. In those cases, the DM was dissected also from its insertion on the deltoid tuberosity. Upon identification of the origin and end tendons (OT and ET), some of the muscle fibres were gently removed from the inner part of the DM to gain access to the muscle structure approximately midway along its length.

The collected measurements underwent statistical analysis. The degrees of correlation were analysed between the width of the origins of particular DM parts, between the length of these parts and the length of the arm, and between the entire width of the DM origin and the length of the arm. The Shapiro-Wilk test was used to test whether the distribution of the values was normal. Spearman's rank correlation coefficient was applied to identify correlations, as it does not require assumptions such as parameter tests of Pearson's linear correlation [12]. All calculations were performed with STATISTICA software (version 10.0 PL).

\section{RESULTS}

\section{General morphology and anthropometric measurements of the DM}

In all specimens, it was possible to precisely identify three parts of the DM: the clavicular (anterior), acromial (middle) and spinal (posterior) parts. In 1 limb, although the spinal part of the DM was clearly separated, it shared a common insertion with the remaining parts (Fig. 1).

Correlations between the entire width of the DM origin and the length of the arm $(p=0.001)$, as well as between the length of the acromial part of the DM and the length of the arm $(p=0.003)$ were found. In addition, statistically significant correlations were found between the width of the spinal attachment and the length of the spinal part $(p=0.002)$, and between the width of the spinal attachment and the length of the arm $(p=0.0008)$. A statistically significant correlation was also observed between the length of the DM spinal part and the length of the arm $(p=0.01)$. Table 1 presents collected results of measurements of the DM taken from 17 upper limbs.

\section{DM attachments with adjacent muscles and fasciae}

In all the cases, the DM was strongly attached to the surrounding structures. The insertion of the DM was

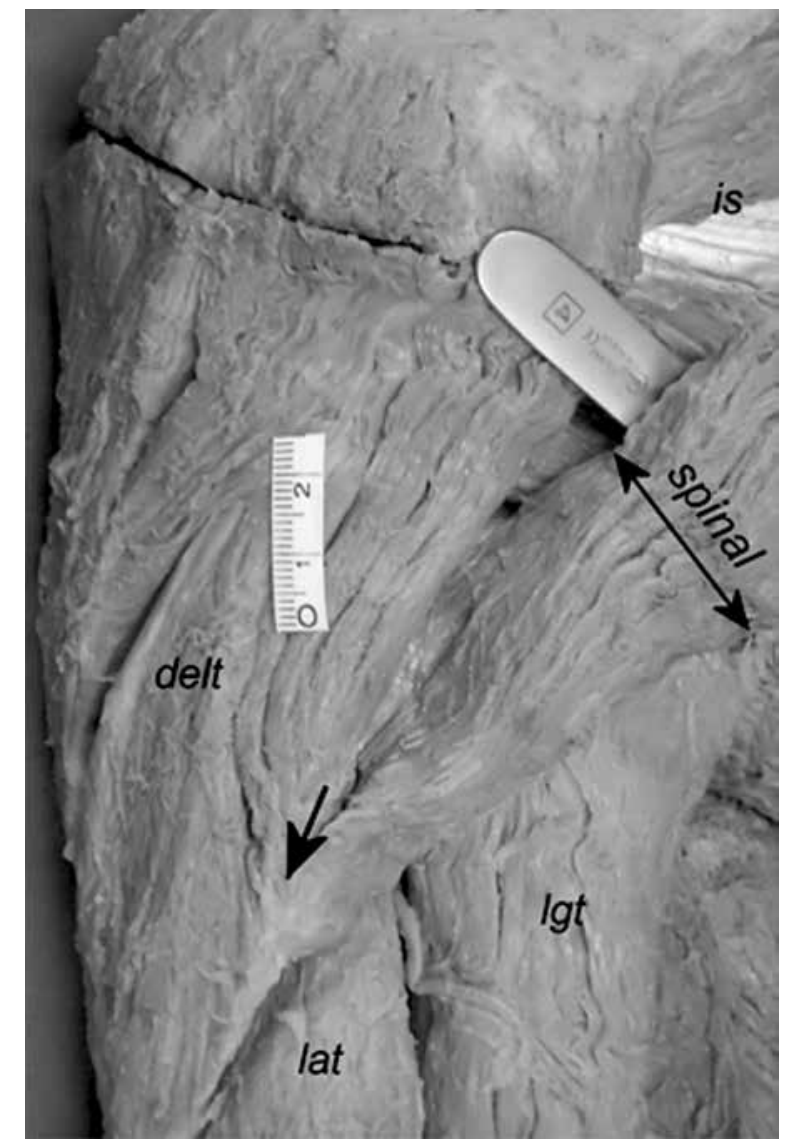

Figure 1. The spinal part of the deltoid is clearly separated. The arrow indicates the insertion common for all parts of the muscle; delt — deltoid; lat — lateral head of the triceps; lgt — long head of the triceps; is - infraspinatus; spinal — separated spinal part of the deltoid.

fused with the lateral intermuscular septum (Fig. 2). Additionally, in all the specimens, a fusion was observed between the anterior band of the DM insertion (insertion of the clavicular part of the DM) and the insertion of the pectoralis major (Fig. 2). The origin of the DM overlapped with and mirrored the insertion of the trapezius.

In the specimens, the inner surface of the spinal part of the DM was attached in several places to the infraspinous fascia and the fascia covering the teres minor (Fig. 3). The tendinous origin of the spinal part of the DM was particularly strongly attached to the infraspinous fascia (Fig. 3). It is noteworthy that the infraspinous fascia may envelop the infraspinatus muscle and the teres minor with 1 common compartment; both of these 2 muscles may also have their own separate fascial compartments, as illustrated in Figure 3. Additionally, the fascia covering the DM was strongly attached to the deep brachial fascia. 
Table 1. Anthropometric measurements of the deltoid muscle

\begin{tabular}{lccccc}
\hline Measured feature & Minimum value [mm] & Maximum value [mm] & Arithmetic mean [mm] & Median & Standard deviation \\
\hline Width of clavicular insertion & 32 & 63 & 49 & 50 & 8 \\
Width of acromial insertion & 41 & 72 & 52 & 52 & 8 \\
Width of spinal insertion & 81 & 148 & 114 & 116 & 18 \\
Entire width of origin & 171 & 275 & 216 & 213 & 28 \\
Length of clavicular part & 162 & 218 & 191 & 194 & 16 \\
Length of acromial part & 125 & 215 & 167 & 168 & 22 \\
Length of spinal part & 176 & 246 & 207 & 205 & 20 \\
Length of arm & 252 & 330 & 297 & 302 & 23 \\
\hline
\end{tabular}

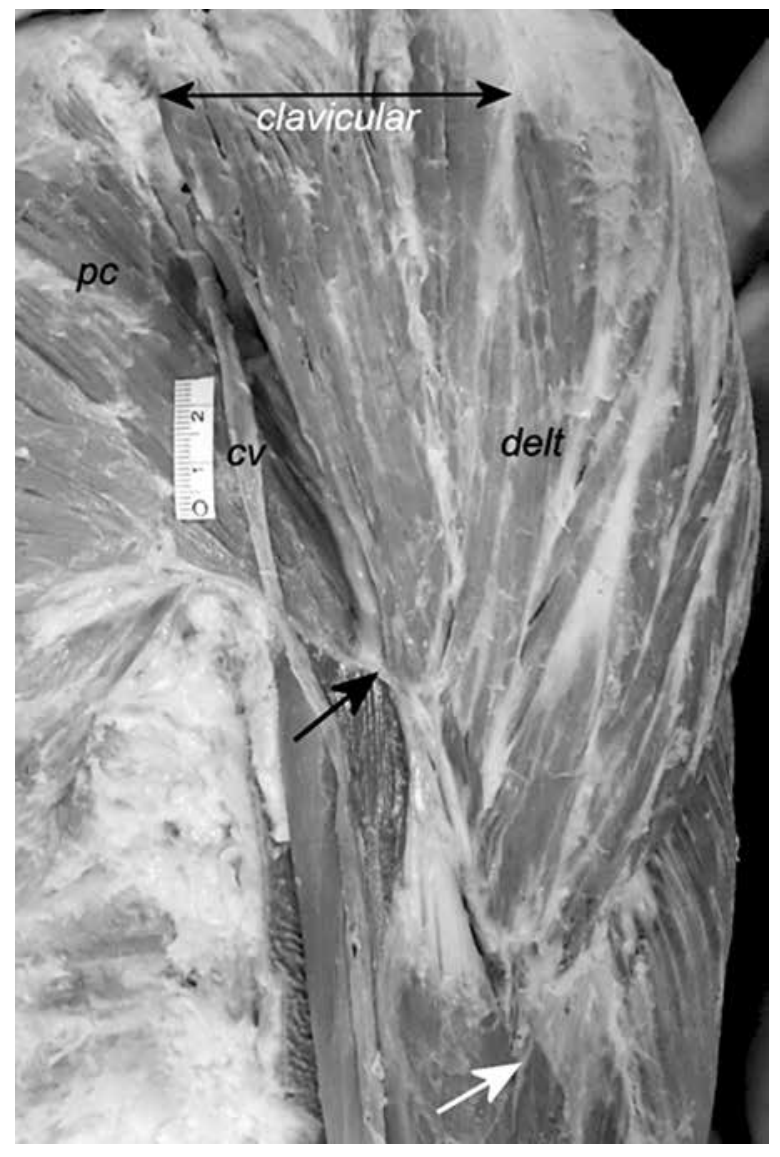

Figure 2. Deltoid muscle — anterior view; delt — deltoid; $p c-$ pectoralis major — clavicular part; $\mathrm{cv}$ - cephalic vein; black arrow - attachment of the tendon of the pectoralis major to the insertion of the clavicular part of the deltoid; white arrow - attachment of the insertion of the deltoid to the lateral intermuscular septum; clavicular — clavicular part of the deltoid.

\section{Internal structure of the DM}

Upon investigation of the internal structure of the deltoid, specific architectonics were observed which consisted of the presence of a tendon system, both in the origins of its particular parts (OT and in the insertion - ET).

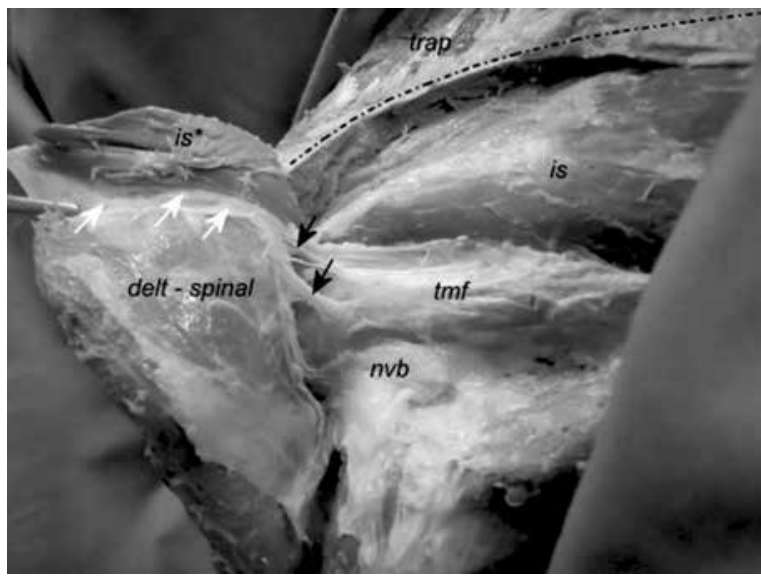

Figure 3. Deltoid muscle being dissected from the origin - posterior view; trap - trapezius; is - infraspinatus (infraspinous fascia partially removed); is ${ }^{*}$ - fibres of the infraspinatus muscle being separated while separating the spinal part of deltoid from its attachment to the spine of the scapula (marked with a dashed line); white arrows - fragment of the infraspinous fascia closely attached to the tendinous origin of the spinal part of the deltoid; black arrows - bands joining the inner deltoid surface with the infraspinous fascia and the fascia covering the teres minor; $n v b-$ neurovascular bundle (before dissection); tmf — fascia covering the teres minor; delt-spinal - spinal part of the deltoid.

\section{Origin tendons (OT)}

After gentle separation of some of the muscle fibres on the inside of the DM, strong tendinous bands were observed in the origins (Fig. 4); in accordance with previous works, these were named origin tendons (OT) [24]. The most invariable OT system occurred in the acromial part of the DM, where 4 to 5 (SD 0.54) OT were found (branching OT were treated as 2 separate structures). The morphology of the acromial part in all the specimens was characteristic of a multipennate muscle (Fig. 4). The length of the acromial part's OT, measured in 6 isolated specimens of the deltoid, varied from 36 to $72 \mathrm{~mm}$, the avera- 


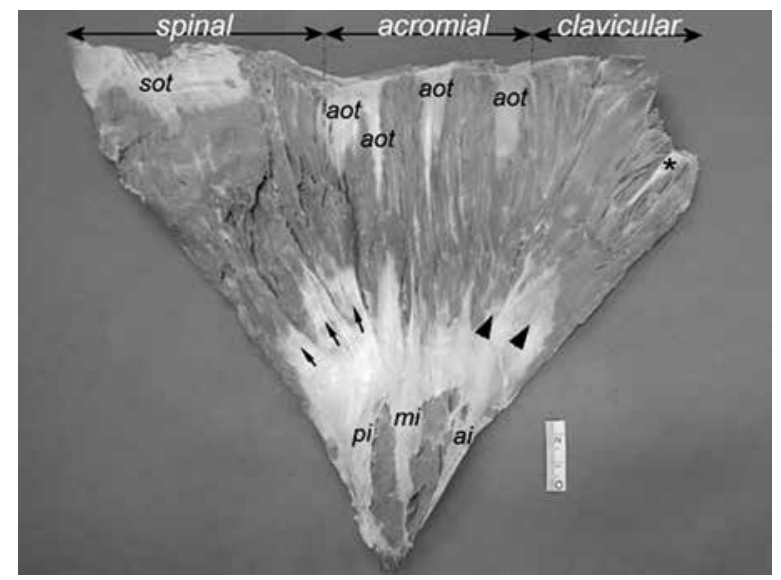

Figure 4. View of the inner part of the deltoid. Some muscle fibres have been gently removed in order to visualise origin and end tendons, thus gaining an insight in the internal structure of the muscle approximately midway in; sot - spinal origin tendon; aot - acromial origin tendon; ${ }^{*}$ - atypical OT in the clavicular part (anatomical variation); arrows - end tendons (ET) of the spinal part; arrowheads - ET of the clavicular part; ai, mi, pi - anterior part, middle part and posterior part of the insertion respectively, along which ET of particular parts of the deltoid are attached.

Parts of the deltoid have been indicated above.

ge being $55 \mathrm{~mm}$ (SD $12 \mathrm{~mm}$ ). Similarly, a strong OT tendon (32-mm-long) was found in the clavicular part solely as a variation ( $1 \mathrm{limb}$ in 6 , Fig. 4). In the spinal part, a flat tendinous origin was observed in all specimens, varying from 72 to $107 \mathrm{~mm}$ in width: the average width being $87 \mathrm{~mm}$ (Fig. 4).

\section{End tendons (ET)}

In all of the 6 isolated specimens of the DM, after cautious resection of the insertion from the deltoid tuberosity, 3 main bands were observed and labelled the anterior part of the insertion (ai), the middle part of the insertion ( $\mathrm{mi}$ ) and the posterior part of the insertion (pi) (Fig. 4). These bands were connected to the end tendons (ET) of particular parts of the DM - tendons of the clavicular part to $a i$, tendons of the acromial part to mi and the spinal part of the DM was inserted to pi (Fig. 4, arrows). In the specimens, the total length of the DM insertion varied from 58 to $72 \mathrm{~mm}$ ( $65 \mathrm{~mm}$ on average, SD $7 \mathrm{~mm}$ ) - with the average being $65 \mathrm{~mm}$ (SD $7 \mathrm{~mm}$ ) for ai; $50 \mathrm{~mm}$ (SD $17 \mathrm{~mm}$ ) for $m i$ and $67 \mathrm{~mm}$ (SD $5 \mathrm{~mm}$ ) for pi.

\section{Innervation scheme of the DM}

In all the specimens, a characteristic 'segmented' innervation scheme of the DM was observed. The AN was divided into an anterior branch (abAN) and

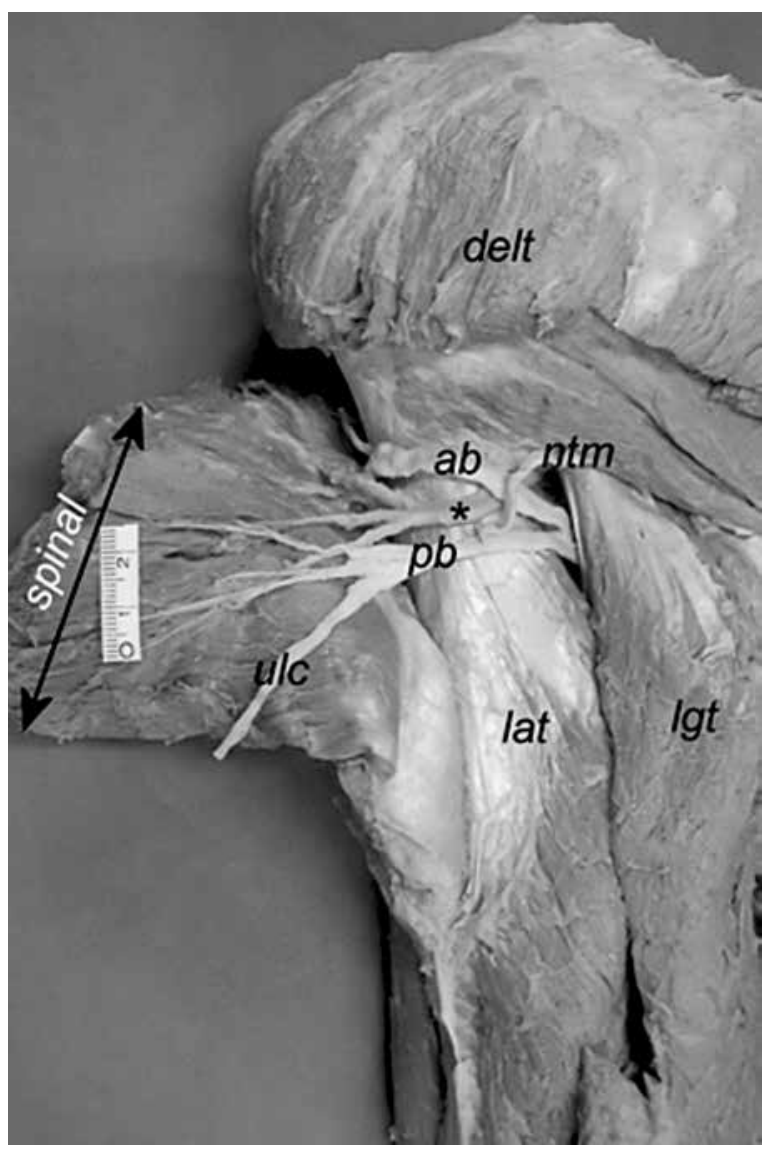

Figure 5. Axillary nerve in quadrangular space - posterior view. Inner surface of the deltoid muscle. Variation II of the deltoid innervation: the spinal part of the deltoid is supplied by nerve sub-branches solely from the posterior branch of the axillary nerve; $a b$ - anterior branch of the axillary nerve; $p b$ - posterior branch; ulc - upper lateral cutaneous nerve of the arm; $n t m$ - nerve to the teres minor; delt — deltoid (cut); lat — lateral head of the triceps; lgt — long head of the triceps; ${ }^{*}$ - posterior circumflex humeral artery; spinal — spinal part of the deltoid.

a posterior branch (pbAN), seen to be located at various distances up to $14 \mathrm{~mm}$ from the quadrangular space, and the division could sometimes be observed at the quadrangular space (Fig. 5). The abAN ran above the mid-length of the DM in all cases.

Two variations of DM innervation were observed. Variation I (Fig. 6), found in 12 specimens (12/17), consisted of cases where the clavicular and the acromial parts were innervated by the abAN sub-branches, while the spinal part was supplied both by abAN sub-branches (anterior fibres) and by the pbAN sub-branches (posterior fibres). Variation II (Fig. 5), found in 5 limbs (5/17), included those cases in which the spinal part did not have double innervation: the abAN innervation area covered only the acromial and clavicular parts while the entire spinal part was 


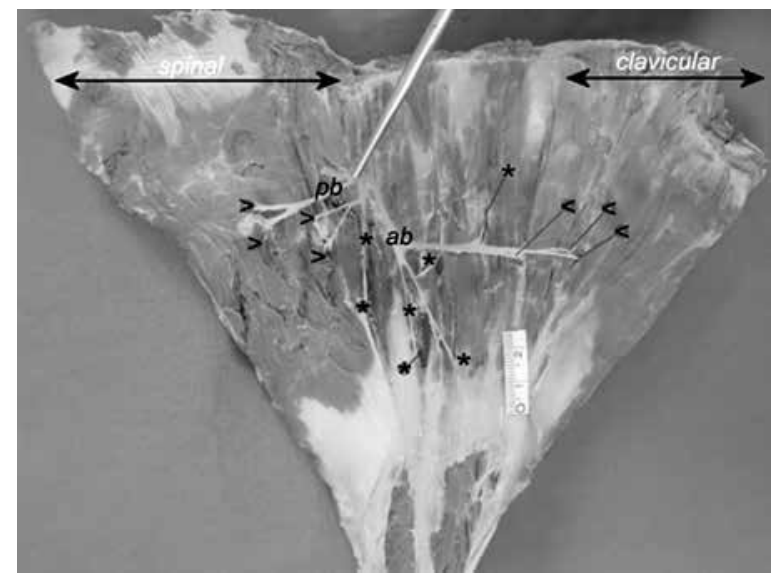

Figure 6. Innervation scheme of the deltoid muscle - variation I. View of the inner surface of the muscle; $a b$ - anterior branch of the axillary nerve; $p b$ - posterior branch; pins marked as ' $<$ ' — sub-branches to the clavicular part; pins marked as ' $*$ ' — sub-branches to the acromial part; pins marked as ' $>$ ' — sub-branches to the spinal part. Variant in which $a b$ has particularly numerous sub-branches reaching the acromial part, splitting particularly low in the acromial part. The clavicular and acromial parts of the deltoid have been marked above.

supplied by the pbAN sub-branches. Both variations had a 'segmented' arrangement of sub-branches connecting with individual parts of the DM, which were particularly distinct in the clavicular and acromial parts. In all cases, the abAN ran in the upper half of the DM, but its sub-branches reached both the lower and the upper half of the muscle (Fig. 6).

\section{DISCUSSION}

Out of the 6 muscles of the pectoral girdle, only the DM originates on both bones of the girdle; the remaining muscles originate only on the scapula. The DM is the largest and the most superficial muscle in the shoulder region. It is triangular, with the tip pointing downwards; it is flat, $\mathrm{v}$-shaped and relatively thick (up to $20 \mathrm{~mm}$ ). In descriptive anatomy and in clinical practice, it is accepted that the DM is divided into three parts, distinguished based on the location of their origins [29, 31, 37]. However, based on function, this division may not be completely accurate [34]. The division of the DM into segments was described by Albinus as early as in 1734 [1]. Literature accounts suggest that the DM may be divisible into segments on the basis of the intramuscular tendon system $[3,24,27,34]$, or alternatively, based on interpretation of the results of functional studies (such as EMG or PET) conducted on live subjects $[5,15,34$, 40]. Gorelick and Brown [15] performed a mechano- myographic assessment of contractile properties of 7 DM segments. Leijnse et al. [24] created a generic model of the origin and end tendons of the DM based on a structural analysis of 8 isolated deltoid muscles. On the basis of positron emission tomography scans of anatomical and functional DM segments, Sakoma et al. [34] propose that the DM can be divided into 7 segments, separated by intramuscular tendons. A literature search reveals many different intramuscular tendon system models, which is reflected in a variety of terms: Audenaert and Barbaix [3] use the term 'septae', Klapper et al. [21] describe such tendons as 'ligament-like bands', and 'Gray's anatomy' [37] refers to 'four intramuscular septa descending from acromion' which imbricate between 'three septa ascending from the deltoid tubercle', Lorne et al. [27] describe the fibrous scaffolding of the DM as 'fibrous bands' and Palastanga et al. [31] use the term 'tendinous slips'. The terms OT and ET, used by Leijnse et al. [24] seem to be the most cohesive and have been therefore adopted consistently in the present work.

In the specimens, the most invariable and most highly-developed intramuscular tendon system was detected in the acromial part of the DM. This part is described as having a multipennate muscle morphology [15, 24, 29, 31, 37], which was confirmed by our observations. Such morphology can be accounted for by the function of the DM - it is the strongest muscle abducting the arm to the shoulder level [31]. The most numerous and, at the same time, the shortest fibres found in the multipennate middle part of the DM give it a lot of strength [31]. Gorelick and Brown [15] suggest that the contractile properties of individual segments are related to their structure - the multipennate acromial part had the slowest contractile properties, while the clavicular and spinal part fibres, involved in flexing and extending, as well as rotating movements of the arm, contracted faster. The arrangement and the contractile properties of muscle fibres in the acromial part of the DM may result from the fact that a lot of upper limb functions require the arm to be kept abducted for a long time, and additionally, acromial part fibres often contract eccentrically when adducting the arm back to the initial position [31].

Measurements of OT length taken in the present study, cannot be compared to other study results, especially in the case of the acromial part, as no such data exists in the literature. A majority of authors agree that 4 OT originate from the acromial part of the DM $[24,37]$. The result obtained in the present 
study group (4 to 5 OT) may follow from the fact that branching OT were treated as 2 separate structures. This observation complies with those of Sakoma et al. [34] on anatomical variations with double tendons in a single segment of the deltoid. Morgan et al. [28] describe the DM insertion as 'long and broad'. In the present study, the length of the DM insertion varied between 58 to $72 \mathrm{~mm}$, with the average being $65 \mathrm{~mm}$ for ai; $50 \mathrm{~mm}$ for $m i$ and $67 \mathrm{~mm}$ for pi. These results are closest to those of Ripsoli et al. [33], in which the average length of ai was $70 \mathrm{~mm}$, the average length of $m i$ was $48 \mathrm{~mm}$, and the average length of pi was $78 \mathrm{~mm}$.

Variants of the DM where it is fused with the pectoralis major, or has additional bands from the trapezius or from the infraspinous fascia, have also been noted in the literature [37]. Examples have also been recorded of a separate spinal part of the DM $[19,20,35]$. It has been emphasised that there may be an attachment between the end of the DM and the lateral intermuscular septum or the brachial fascia $[30,34,37]$. A detailed description of anatomical variations of the infraspinous fascia is provided by Chafik et al. [6]. In the present study, the spinal part of the DM also displayed attachment to the infraspinous fascia, in all specimens.

There are functional reasons behind correlations found in the DM parameters of the specimens and they comply with anthropometric measurements results available in the literature. Inicka [18] demonstrated that the length of the belly parts of the limb muscles, the DM included, depends on body height and limb length, which was confirmed in the specimens used in this study: a distinct correlation was found between arm length, and the length of the acromial part and the spinal part of the DM. As Ilnicka [18] notes, arm length is a skeletal property which positively correlates with almost all muscle properties, irrespective of the muscle topography. On the other hand, muscle attachment located on the clavicle has more variety [18]. Thus, it seems that muscle length determines motion range to the greatest extent, while its architecture determines muscle function and motion control [16, 26, 41]. Muscle formation, including such parameters as the length of its contractile part, tendon length or attachment width, depends both on genetic factors and on the type of work it does [16, 17, 31, 41]. Fridén and Lieber [14] emphasizes the high degree of specialisation of the morphology of upper limb muscles.
Due to its clinical importance, research performed so far on DM innervation has been focused on the topography (route) of the AN. Even though variations of the AN have been subject of a lot of research $[2,4,7,13,32,39]$, there are few studies of the detailed scheme of DM innervation [4, 39]. Anatomical variations of innervation of individual parts of the DM are clinically relevant. The clavicular and acromial parts are innervated by the abAN, as was found in almost all specimens in the present study, but the spinal part, as confirmed by Uz et al. [39], may either be innervated only by the pbAN, or may have double innervation by the abAN and pbAN. Uz et al. [39] note such double innervation in $30 \%$ of cases. In our study, double innervation of the spinal part was found in a larger percentage of cases: 12 limbs out of 17. Such variations may be clinically significant, taking into account different surgical approaches, as well as transfer of the DM spinal part to the long head of the triceps, which is sometimes performed [10, 14, 39]. The spinal part of the DM contributes up to $20 \%$ to arm extension (Crouch et al. [10]). Some studies indicate that the lateral pectoral nerve may also participate in DM innervation [36]. Such a variation was not found in the present study. Detailed innervation scheme of the DM was not systematically considered in the context of the muscle segments of the DM, even in the latest research [24, 34]. Our observations of the DM innervation scheme, with multiple sub-branches splitting at regular intervals from the main branches of the $\mathrm{AN}$, are in line with the concept of anatomical and functional segmentation of the DM $[3,5,24,34,40]$.

\section{CONCLUSIONS}

The study confirmed the existence of a characteristic segmented innervation scheme of the DM which corresponds with the segmented morphology of its individual parts. An analysis of the internal structure of the muscle specific architectonics based on the tendon system was also presented. In all the cases, the DM was strongly attached to the surrounding structures. Additionally, the anthropometric measurements revealed that the arm length is a skeletal property which positively correlates with almost all DM properties.

\section{ACKNOWLEDGMENTS}

The article was financed by the Medical University of Lodz, as part of research task no. 502-03/5-076-01/ /502-54-051. 


\section{REFERENCES}

1. Albinus BS (1734) Historiae musculorum hominis. T. Haak \& H. Mulhovium, Leiden, pp. 420-423.

2. Apaydin N, Tubbs RS, Loukas M, Duparc F (2010) Review of the surgical anatomy of the axillary nerve and the anatomic basis of its iatrogenic and traumatic injury. Surg Radiol Anat, 32: 193-201.

3. Audenaert E, Barbaix E (2008) Separate segments within the deltoidmuscle: Anatomical variants or wishful thinking? Int J Shoulder Surg, 2: 69-70.

4. Ball CM, Steger T, Galatz LM, Yamaguchi K (2003) The posterior branch of the axillary nerve: an anatomic study. J Bone Joint Surg Am, 85: 1497-1501.

5. Brown JM, Wickham JB, McAndrew DJ, Huang XF (2007) Muscles within muscles: coordination of 19 muscle segments within three shoulder muscles during isometric motor tasks. J Electromyogr Kinesiol, 17: 57-73.

6. Chafik D, Galatz LM, Keener JD, Kim HM, Yamaguchi K (2013) Teres minor muscle and related anatomy. J Shoulder Elbow Surg, 22: 108-114.

7. Cetik O, Uslu M, Ibrahim A, Comert A, Tekdemir I, Cift H (2006) Is there a safe area for the axillary nerve in the deltoid muscle? J Bone Joint Surg, 88A: 2395-2399.

8. Cheung S, Fitzpatrick M, Lee TQ (2009) Effects of shoulder position on axillary nerve positions during the split lateral deltoid approach. J Shoulder Elbow Surg, 18: 748-755.

9. Choi, HR, Kondo S, Mishima S, Shimizu T, Hasegawa Y, Ida K (2001) Axillary nerve injury caused by intradeltoid muscular injection: a case report. J Shoulder Elbow Surg, 10: 493-495.

10. Crouch DL, Plate JF, Li Z, Saul KR (2013) Biomechanical contributions of posterior deltoid and teres minor in the context of axillary nerve injury: a computational study. J Hand Surg Am, 38: 241-249.

11. Davidson LT, Carter GT, Kilmer DD, Han JJ (2007) latrogenic axillary neuropathy after intramuscular injection of the deltoid muscle. Am J Phys Med Rehabil, 86: 507-511.

12. Domański C, Iwaszkiewicz-Zasłonka A, Jaszewski R, Zasłonka J (2003) Zastosowanie metod statystycznych w badaniach pacjentów z chorobą niedokrwienną serca leczonych operacyjnie. Wydawnictwo Uniwersytetu Łódzkiego, Łódź.

13. Dy CJ, Kitay A, Garg R, Kang L, Feinberg JH, Wolfe SW (2013) Neurotization to innervate the deltoid and biceps: 3 cases. J Hand Surg Am, 38: 237-240.

14. Fridén J, Lieber RL (2001) Quantitative evaluation of the posterior deltoid to triceps tendon transfer based on muscle architectural properties. J Hand Surg Am, 26: 147-155.

15. Gorelick ML, Brown JM (2007) Mechanomyographic assessment of contractile properties within seven segments of the human deltoid muscle. Eur J Appl Physiol, 100: 35-44.

16. Herring SW, Grimm AF, Grimm BR (1984). Regulation of sarcomere number in skeletal muscle: a comparison of hypotheses. Muscle Nerve, 7: 161-173.

17. Holzbaur KRS, Murray WM, Delp SL (2005) A model of the upper extremity for simulating musculoskeletal surgery and analyzing neuromuscular control. Ann Biomed Eng, 33: $829-40$

18. Ilnicka L (1999) Zmienność cech makroskopowych wybranych mięśni i ich związki z ogólną budową ciała człowieka (Z badań antropomorfologicznych osobników żywych). AWF, Warszawa, pp. 92, 103-104, 215-216.

19. Kamburoğlu HO, Boran OF, Sargon MF, Keçik A (2008) An unusual variation of deltoid muscle. Int J Shoulder Surg, 2: 62-63.

20. Kayikçioglu A, Celik HH, Yilmaz E (1993) An anatomic variation of the deltoid muscle (case report). Bull Assoc Anat, 77: 15-66.
21. Klapper RJ, Jobe FW, Matsuura P (1992) The subscapularis muscle and its glenohumeral ligament like bands: a histomorphologic study. Am J Sports Med, 20: 307-310.

22. Klepps S, Auerbach J, Calhon O, Lin J, Cleeman E, Flatow E (2004) A cadaveric study on the anatomy of the deltoid insertion and its relationship to the deltopectoral approach to the proximal humerus. J Shoulder Elbow Surg, 13: 322-327.

23. Kumar VP, Satku K, Liu I, Shen Y (1997) The anatomy of the anterior origin of the deltoid. I Bone loint Surg, 79: 680-683.

24. Leijnse JN, Han SH, Kwon YH (2008) Morphology of deltoid origin and end tendons - a generic model. J Anat, 213: 733-742.

25. Lewicky YM, Sheppard JE, Ruth JT (2007) The combined olecranon osteotomy, lateral paratricipital sparing, deltoid insertion splitting approach for concomitant distal intra-articular and humeral shaft fractures. J Orthop Trauma, 21: 133-139.

26. Lieber RL, Fridén J (2000) Functional and clinical significance of skeletal muscle architecture. Muscle Nerve, 23: 1647-66.

27. Lorne E, Gagey O, Quillard J, Hue E, Gagey N (2001) The fibrous frame of the deltoid muscle. Its functional and surgical relevance. Clin Orthop, 386: 222-225.

28. Morgan SJ, Furry K, Parekh AA, Agudelo JF, Smith WR (2006) The deltoid muscle: an anatomic description of the deltoid insertion to the proximal humerus. J Orthop Trauma, 20: 19-21.

29. Muscolino JE (2005), The muscular system manual. The sceletal muscles of the human body. Mosby Elsevier, Maryland Heights, Missouri, pp. 121-123.

30. Myers TW (2009) Anatomy trains. Myofascial meridians for manual and movement therapists. Churchill Livingstone Elsevier, Edinburgh, London, New York, pp. 160-162.

31. Palastanga N, Field D, Soames R (2006) Anatomy and Human Movement: Structure and function. Butterworth-Heinemann, Elsevier, Edinburgh, London, New York, pp. 73-75.

32. Rashid A, Abdul-Jabar H, Lam F (2008) Nerve injury associated with shoulder surgery. Current Orthopaedics, 22: 284-288.

33. Rispoli DM, Athwal GS, Sperling JW, Cofield RH. (2009): The anatomy of the deltoid insertion. J Shoulder Elbow Surg, 18: 386-390.

34. Sakoma Y, Sano H, Shinozaki N, Itoigawa Y, Yamamoto N, Ozaki T, Itoi E (2011) Anatomical and functional segments of the deltoid muscle. J Anat, 218: 185-190.

35. Sawant SP, Shaikh ST, More RM (2012) A variant deltoid muscle: a case report. IJCRR, 4: 78-82.

36. Solomon LB, Ravindranath N, Vidic B, Dym M (1997) Anatomical variant of the lateral pectoral nerve innervating the anterior portion of the deltoid muscle: a case report. Anat Rec, 249: 506-509.

37. Standring S ed. (2008) Gray's anatomy. The anatomical basis of clinical practice. $40^{\text {th }} \mathrm{Ed}$. Churchill Livingstone, Edinburgh, pp. 809-810.

38. Stecco C, Gagliano G, Lancerotto L, Tiengo C, Macchi V Porzionato A, De Caro R, Aldegheri R (2010) Surgical anatomy of the axillary nerve and its implication in the transdeltoid approaches to the shoulder. J Shoulder Elbow Surg, 19: 1166-1174.

39. Uz A, Apaydin N, Bozkurt M, Elhan A (2007) The anatomic branch pattern of the axillary nerve. J Shoulder Elbow Surg, 16: 240-244.

40. Wickham JB, Brown JM (1998) Muscles within muscles: the neuromotor control of intra-muscular segments. Eur J Appl Physiol Occup Physiol, 78: 219-225.

41. Zuurbier CJ, Everard AJ, van der Wees P, Huijing PA (1994) Length-force characteristics of the aponeurosis in the passive and active muscle condition and in the isolated condition. J Biomech, 27: 445-453. 